\title{
Clinical efficacy and safety of donepezil in the treatment of Alzheimer's disease in Chinese patients
}

This article was published in the following Dove Press journal:

Clinical Interventions in Aging

\author{
Nan Zhang ${ }^{1,2}$ \\ Marc L Gordon ${ }^{3,4}$ \\ 'Department of Neurology, Tianjin \\ Medical University General Hospital, \\ Tianjin Neurological Institute, \\ Tianjin, People's Republic of China; \\ ${ }^{2}$ Department of Neurology and \\ Neurosurgery, Tianjin Medical \\ University General Hospital Airport \\ Hospital, Tianjin, People's Republic of \\ China; ${ }^{3}$ The Litwin-Zucker Research \\ Center, The Feinstein Institute for \\ Medical Research, Northwell Health, \\ Manhasset, NY, USA; ${ }^{4}$ Departments of \\ Neurology and Psychiatry, Donald and \\ Barbara Zucker School of Medicine \\ at Hofstra/Northwell, Hempstead, \\ NY, USA
}

\begin{abstract}
Donepezil, an acetylcholinesterase inhibitor (AChEI), has been widely used to treat Alzheimer's disease (AD) in China. However, there are few studies focusing on the efficacy and safety of donepezil in Chinese patients. In this review, we discuss 1) the efficacy of donepezil and its comparison with other AChEIs or memantine, 2) the therapeutic responses to donepezil and its influencing factors, and 3) the safety and tolerability of donepezil in Chinese patients with different stages of $\mathrm{AD}$ and amnestic mild cognitive impairment, and further compare the similarities and differences of the results between Chinese studies and previous Western studies that predominantly enrolled Caucasian subjects. We include Chinese clinical trials and other well-designed studies investigating donepezil or using donepezil as a positive control, in which the efficacy and/or safety of donepezil have been analyzed. Based on these studies, donepezil has been shown to be effective and safe in Chinese AD patients and may impact AD biomarkers, such as hippocampal atrophy, $A \beta$, and tau. In addition, the therapeutic response to donepezil may be influenced by apolipoprotein E or cytochrome P450 2D6 polymorphism.
\end{abstract}

Keywords: Alzheimer's disease, amnestic mild cognitive impairment, donepezil, acetylcholinesterase inhibitor, efficacy, safety

\section{Introduction}

Alzheimer's disease (AD) is becoming one of the most burdensome diseases in China, with a prevalence of $3.21 \%{ }^{1}$ to $3.5 \%,{ }^{2}$ and an estimated incidence of $8.2 / 1,000$ person-years ${ }^{3}$ among the population aged $\geq 65$ years. It has been estimated that there were $\sim 5.69$ million AD patients in China in $2010 .{ }^{4}$ However, since the median duration between symptom onset and first medical visit was 24 months, ${ }^{5}$ most AD patients were at the moderate or severe stage when first diagnosed and treated. ${ }^{6}$

$\mathrm{AD}$ is a neurodegenerative disorder, characterized by memory and other cognitive function deficits, progressive decline of activities of daily living (ADLs), and behavioral and psychological symptoms of dementia (BPSD), with pathological hallmarks of neuritic plaques (A $\beta$ pathology) and neurofibrillary tangles (tau pathology). The contribution of cholinergic system deficiency to cognitive dysfunction and $A \beta$ pathology in AD has been previously demonstrated. ${ }^{7}$ Donepezil, which is a reversible noncompetitive acetylcholinesterase inhibitor (AChEI), has shown efficacy on cognitive function, ADLs, BPSD, and global function across the mild, moderate, and severe stages of AD worldwide. ${ }^{8-10}$

Although donepezil was approved for the treatment of mild to moderate AD in 2006 and severe AD in 2017 by the Food and Drug Administration in China, only a
Correspondence: Nan Zhang Department of Neurology, Tianjin Medical University General Hospital, I54, Anshan Road, Tianjin 300052 , People's Republic of China

Tel $+8622608 \mathrm{I} 4504$

Fax +862260814592

Email nkzhangnan@yeah.net (c) (i) (5) 2018 Zhang and Gordon. This work is published and licensed by Dove Medical Press Limited. The full terms of this license are available at https://www.dovepress.com/terms.php cc. ${ }_{\mathrm{BY}} \mathrm{NC}$ and incorporate the Creative Commons Attribution - Non Commercial (unported, v3.0) License (http://creativecommons.org/licenses/by-nc/3.0/). By accessing the work you hereby accept the Terms. Non-commercial uses of the work are permitted without any further permission from Dove Medical Press Limited, provided the work is properly attributed. For permission for commercial use of this work, please see paragraphs 4.2 and 5 of our Terms (https://www.dovepress.com/terms.php). 
few randomized, double-blind studies investigating donepezil in Chinese patients have been reported. Moreover, the therapeutic response to donepezil might differ between Chinese patients and Caucasian patients due to pharmacogenetic factors such as cytochrome P450 enzyme (CYP) polymorphisms or apolipoprotein E (APOE) $\varepsilon 4$ allele frequency (which is lower in Chinese ${ }^{11}$ than in Western populations). In this paper, we review the efficacy and safety of donepezil in Chinese patients with all stages of AD and amnestic mild cognitive impairment (aMCI), and explore the factors influencing response to donepezil treatment.

\section{Literature}

We sought to include studies about donepezil treatment in Chinese AD patients, preferably published in English, and well-designed studies reported in Chinese. Studies were identified through an electronic search of three databases: PubMed, China National Knowledge Infrastructure (CNKI), and Wanfang. Our initial screen returned 1,840 results from PubMed, 649 from CNKI, and 1,046 from Wanfang. We excluded 1) duplicates within and between the databases, 2) studies of animals, 3) studies not conducted in Chinese patients, and 4) studies with no analysis of donepezil when it was used as the basic treatment or a positive control. In total, 18 English papers and 9 Chinese papers were finally included in this review. Studies used to analyze the efficacy of donepezil in Chinese patients with $\mathrm{AD}$, of which more than half were published in Chinese, were classified according to the level of evidence guidelines of the American Academy of Neurology (Table 1). There were substantial limitations of some of the Chinese studies included in this review. First, several studies were inadequate in study design, such as randomization, blinding, and sample size. Secondly, they were heterogeneous in terms of inclusion criteria, dosage, duration, outcome measures, and comparators.

\section{The efficacy of donepezil in mild to moderate AD Donepezil vs placebo}

The first multicenter, randomized, placebo-controlled clinical trial to evaluate the efficacy and safety of donepezil in China was published in 2002, in which patients with mild to moderate $\mathrm{AD}$ had improvement in cognitive function, ADLs, and global function after 12-week treatment with $5 \mathrm{mg} / \mathrm{d}$ donepezil and performed better in assessments of the MiniMental State Examination (MMSE), the Clinical Dementia Rating (CDR), and the ADL than placebo. ${ }^{12}$ In a long-term prospective study including mostly patients at the mild or moderate stages of $\mathrm{AD}$, the donepezil group exhibited better efficacy on cognitive function, ADLs, and global function even after 72 months of treatment, while there was a high dropout rate in both the donepezil group (55.8\%) and the control group $(74.4 \%)$ by the endpoint. ${ }^{13}$

\section{Donepezil vs other AChEls}

Compared to the first approved AChEI tacrine, donepezil showed equivalent improvement in cognitive function and ADLs, and better tolerability and safety in Chinese patients with mild to moderate AD. ${ }^{14}$ Moreover, donepezil showed a similar effect as rivastigmine on ameliorating disease progression in a longitudinal observational study. ${ }^{15}$ In a head-to-head study comparing galantamine and donepezil, both medications showed improvement in the Alzheimer's Disease Assessment Scale-Cognitive Subscale (ADAS-cog) score after 16 weeks of treatment. ${ }^{16}$ The total ADAS-cog, ADL, and Neuropsychiatric Inventory (NPI) scores were not significantly different between the two groups, although galantamine was superior for improving language function on ADAS-cog and had a higher response rate to treatment compared to donepezil. However, only $69 \%$ of patients receiving galantamine and $61 \%$ of patients receiving donepezil took the highest maintenance dose (galantamine $24 \mathrm{mg} / \mathrm{d}$ or donepezil $10 \mathrm{mg} / \mathrm{d}$ ) at the endpoint in this study. Shao et al compared the efficacy of four AChEIs in combination with memantine, including donepezil, rivastigmine, galantamine, and huperzine $\mathrm{A}$, in mild to moderate $\mathrm{AD}$ patients, and found improvement in the MMSE and the ADL scores after 24-week treatment with any AChEIs combined with memantine although only memantine plus huperzine A was statistically superior to memantine plus placebo. ${ }^{17}$

\section{Donepezil vs memantine}

In a previous multicenter study, donepezil used as a positive control to test the efficacy of memantine in Chinese AD patients showed improvement after 24-week treatment and had equivalent efficacy to memantine in all outcome measures, including the Clinician's Interview-Based Impression of Change plus Caregiver Input (CIBIC-plus), the ADAScog, the 20-item ADL, the NPI, and the MMSE. ${ }^{18}$ For the secondary analysis, donepezil resulted in an improved score for naming ability on the ADAS-cog compared to memantine, whereas memantine more effectively alleviated agitation scores on the NPI than donepezil in the mild to moderate subgroup. ${ }^{19}$ In another multicenter study, donepezil had a trend toward better improvement in daily living after 8-week treatment compared to memantine, but there was 


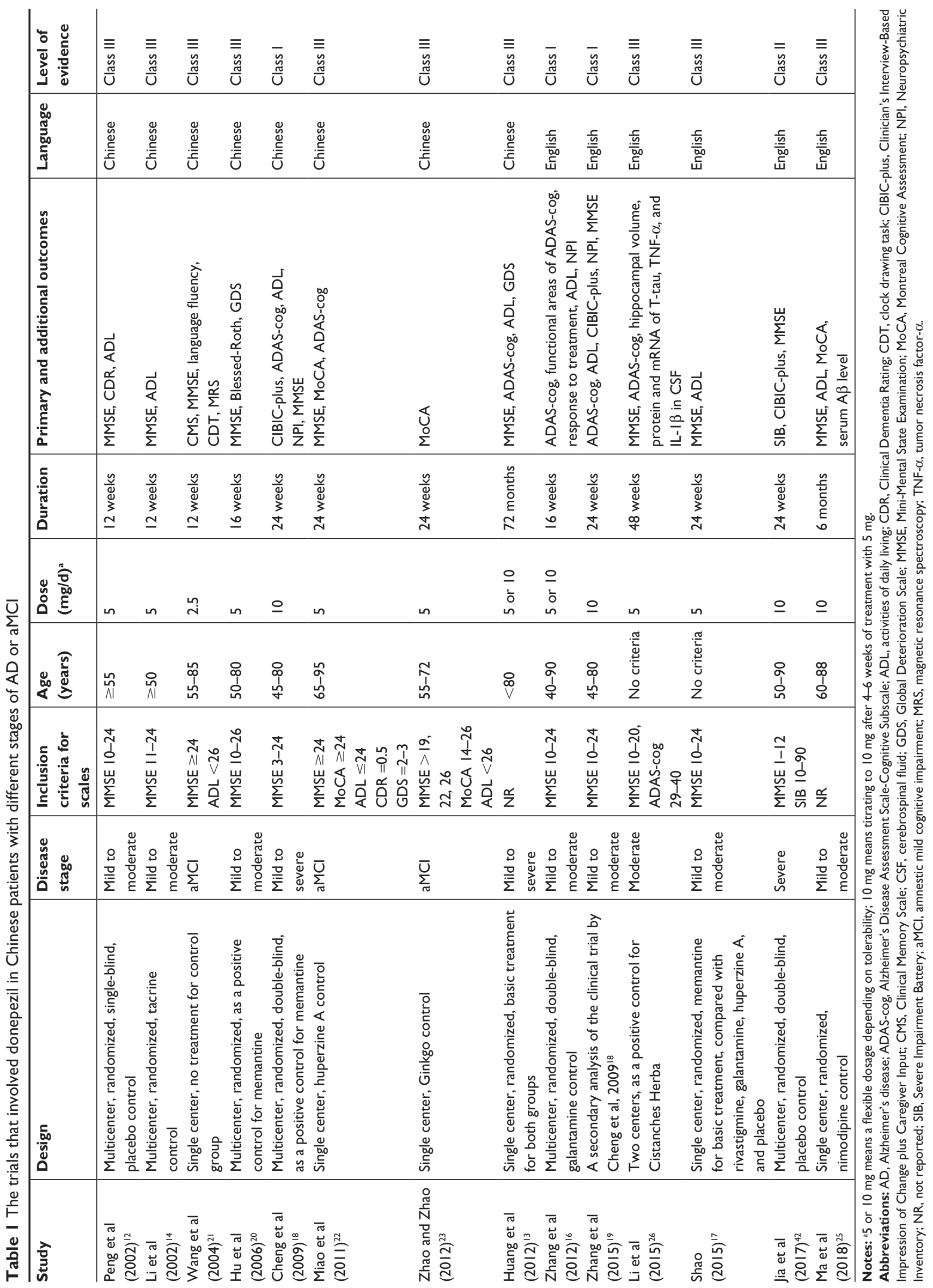


no difference in any outcome between the two drugs at the 16-week endpoint, where the MMSE and Blessed-Roth scores were significantly improved and global function was not changed by either drug. ${ }^{20}$

\section{Effects on aMCl}

Wang et al reported that low dose of donepezil $(2.5 \mathrm{mg} / \mathrm{d})$ could improve memory ability and total MMSE score of Chinese aMCI patients after 12-week treatment. ${ }^{21}$ Moreover, aMCI patients who received donepezil showed better performance in MMSE and ADAS-cog testing than those who took huperzine A after 24 weeks, and $42.3 \%$ of aMCI patients were responders to donepezil vs $17.6 \%$ to huperzine A (defined as MMSE or Montreal Cognitive Assessment [MoCA] score increase of $0.5 \mathrm{SD}$, and ADAS-cog score decreases no less than 4). ${ }^{22}$ Another study using MoCA as an outcome measure demonstrated efficacy of donepezil in aMCI and showed greater improvement with donepezil than with Ginkgo biloba after 24-week treatment, especially in digit span, animal fluency, and delayed recall. ${ }^{23}$

\section{Effects on clinical biomarkers}

Cognitive function of mild Chinese AD patients, especially memory, orientation, and visual instruction, accompanied by P300 latency could be improved after $5 \mathrm{mg} / \mathrm{d}$ donepezil treatment for 22-23 weeks. ${ }^{24}$ In a randomized study, donepezil improved MMSE, MoCA, and ADL scores after 6 months of treatment more so than nimodipine, and decreased the serum $\mathrm{A} \beta$ level in AD patients. ${ }^{25}$ However, all patients also received "conventional treatment", which was not explicitly clarified in that study. Likewise, in addition to cognitive improvement, donepezil slowed down hippocampal atrophy, and decreased mRNA and protein expressions of total tau, tumor necrosis factor- $\alpha$, and IL- $1 \beta$ in the cerebrospinal fluid after 48 weeks of treatment in a small sample study evaluating Cistanches Herba in moderate AD patients. ${ }^{26}$

Generally, the evidence for the efficacy of donepezil in Chinese patients with mild to moderate $\mathrm{AD}$ is consistent with previous findings in Western countries. Donepezil showed benefit on cognitive function, ADLs, and global function (improved rate of 59.8\% based on CIBIC-plus in a Chinese all-stage study, ${ }^{18} 52 \%$ based on Clinical Global Impression of Change in a Japanese study [5 mg/d], ${ }^{27}$ and $25 \%$ in Western studies). ${ }^{8,28}$ Donepezil may have long-term benefits for AD patients, although this needs further investigation due to the high withdrawal rate in both Chinese studies and previous Western studies. ${ }^{29-32}$ The strengths and weaknesses of donepezil in the treatment of mild to moderate Chinese
AD patients compared to other AChEIs and memantine are still unclear, since few well-designed studies focused on this comparison. In terms of aMCI, findings of Chinese studies are consistent with those of Western research which suggested slight cognitive improvement with donepezil, although long-term benefit has not been established. ${ }^{33-35}$ Moreover, the effect of donepezil on neuroimaging markers and peripheral biomarkers has also been observed in Western studies, for example, reduced whole brain ${ }^{36}$ and hippocampal ${ }^{37}$ atrophy rate in patients with aMCI, and increased $\mathrm{A} \beta$ concentration in the cerebrospinal fluid in patients with AD. ${ }^{38}$

\section{The efficacy of donepezil on moderate to severe AD}

Donepezil has been demonstrated to be efficacious and has been approved by the Food and Drug Administration in the United States and regulatory authorities of other countries for the treatment of moderate to severe AD. ${ }^{9,39}$ It has been further observed that maintaining donepezil treatment had cognitive and functional benefits compared to withdrawing donepezil in moderate to severe AD patients. ${ }^{40}$ In an investigative study held in 60 hospitals of 40 cities in China, 808 dementia patients $(67 \%$ at moderate to severe stage; $56.9 \%$ AD type) received donepezil treatment for 12 weeks. Cognitive function, ADLs, and psychological and mood symptoms improved at the endpoint, although only MMSE was analyzed in disease-specific subgroups in this study. ${ }^{41}$ In post hoc analysis of the previously cited Chinese multicenter study, ${ }^{18}$ donepezil showed equivalent efficacy as compared to memantine on cognitive function, ADLs, BPSD, and global function in patients with moderate to severe AD.

Recently, a multicenter, double-blind, randomized, placebo-controlled study showed improvements in cognitive function and global function after 24-week treatment with donepezil in Chinese patients with severe AD, which facilitated the approval of donepezil for severe AD in China. ${ }^{42}$ Compared to the results of a subgroup analysis from the moderate to severe AD study, ${ }^{43}$ and a pooled data analysis ${ }^{44}$ that includes a multinational study, ${ }^{10}$ a Swedish nursing home study, ${ }^{39}$ and a Japanese study ${ }^{45}$ focusing on patients with severe $\mathrm{AD}$, the mean treatment difference on Severe Impairment Battery (SIB) was 4.8 (Chinese study) vs 7.42 (post hoc analysis) vs 6.4 (pooled analysis), and the rate of improvement or no change on CIBIC-plus or Clinical Global Impression of Improvement was $74.7 \%$ vs $55.6 \%$ vs $70.8 \%$, respectively. Effects on BPSD were not assessed in the Chinese study and were inconclusive from previous clinical trials. 


\section{Plasma concentration and response to donepezil in Chinese AD patients}

In two previous studies from the group at Kaohsiung Medical University Hospital, the plasma concentration of donepezil after 6 months of treatment with a dosage of $5 \mathrm{mg} / \mathrm{d}$ in Chinese AD patients was 57.0 \pm 32.2 (mean \pm SD) and $68.7 \pm 33.3 \mathrm{ng} / \mathrm{mL} .{ }^{46,47}$ However, the correlation between donepezil concentration and cognitive function was contradictory in these two studies. In the first study, ${ }^{46} 60 \%$ of newly diagnosed $\mathrm{AD}$ patients were deemed to have good cognitive response to donepezil according to MMSE score change ( $\geq 0$ from baseline), and higher initial MMSE score and higher plasma concentration of donepezil were significantly associated with poor therapeutic response in cognition. In the same study, $57.1 \%$ of patients were deemed to have a good response in global status based on CDR sum of boxes (CDR-SB) score change ( $\leq 0$ from baseline), and higher initial MMSE and CDR-SB, but not donepezil plasma concentration, were significantly associated with poor therapeutic response in global status. APOE $\varepsilon 4$ status and gender were not significantly associated with the therapeutic outcomes in cognition or global status. In the second study, ${ }^{47}$ increased donepezil plasma concentration was significantly associated with the improvement of long-term memory as assessed using the Cognitive Ability Screening Instrument (CASI) among 37 patients with newly diagnosed mild stage AD taking donepezil $5 \mathrm{mg} / \mathrm{d}$, after adjusting for age, sex, education, and APOE genotype. Similarly, no relationship was observed between APOE genotype and annual disease progression of mild to moderate $\mathrm{AD}$ patients receiving treatment with any AChEIs or memantine in their longitudinal study. ${ }^{15}$ In another study, they reported a response rate (defined as CASI score change $\leq 0$ from baseline) of $36.7 \%$ in 196 patients with mild to moderate AD after 1 year of treatment with donepezil $(5 \mathrm{mg} / \mathrm{d}$ for 28 days followed by $10 \mathrm{mg} / \mathrm{d}$ thereafter), and further observed that white matter changes in the frontal area and basal ganglia were significantly associated with a reduced therapeutic response. ${ }^{48}$

Findings about the relationships between donepezil plasma concentration or therapeutic responses to donepezil and genetic polymorphisms of APOE or genes that affect the metabolism or transport of donepezil, such as CYP2D6, have been inconsistent. For instance, no correlation was found between either APOE genotype or CYP2D6 rs1080985 polymorphism and response to donepezil $5 \mathrm{mg} / \mathrm{d}$ for 6 months in a study which examined 208 Chinese mild to moderate AD patients, with an overall response rate of $68.9 \%$ (defined as no deterioration in MMSE score).$^{49}$ However, in another study,
CYP2D6 polymorphism $(* 1 / * 10$ or $* 10 / * 10$ as compared with $* 1 / * 1$ ), but not APOE $\varepsilon 4$ status, was associated with higher donepezil plasma concentration and better cognition scores in Chinese mild to moderate AD patients treated with donepezil $5-10 \mathrm{mg} / \mathrm{d}$ for 6 months..$^{50}$ They further demonstrated that APOE $\varepsilon 3$ and the CYP2D6 rs 1065852 polymorphism influence the steady-state plasma concentration of donepezil, resulting in different therapeutic responses on a stable dose of donepezil for at least 3 months. ${ }^{51,52}$ Recently, they reported that the therapeutic response to donepezil might also be influenced by ABCA1 rs2230806 polymorphism in Chinese AD patients. ${ }^{53}$

Although the pharmacogenomic properties of donepezil have been investigated in different ethnic groups in addition to the Chinese population, including APOE ع4, CYP2D6 (especially, rs1080985), and butyrylcholinesterase, the results have been inconclusive. A meta-analysis ${ }^{54}$ indicates that APOE $\varepsilon 4$ per se is independent of, but may interact with CYP2D6 rs1080985 to influence the therapeutic response to donepezil. In addition, patients who carry the normal function CYP2D6 alleles have better response to donepezil than those carrying increased function alleles. All those results were preserved even after excluding studies of Chinese AD patients. Therefore, it seems that the therapeutic response to donepezil is not fundamentally different between Chinese and Caucasian or other ethnic groups, but the pharmacogenomic properties and metabolic features of donepezil should be further investigated in different races.

\section{Safety and tolerability of donepezil}

Donepezil has been shown to be safe and well tolerated compared to placebo, huperzine A, galantamine, and memantine and much better than tacrine in Chinese clinical trials, with dropout and adverse event (AE) rates during 12-24 weeks of treatment in mild to moderate $\mathrm{AD}$ patients ranging from $0 \%$ to $8.4 \%$ and from $4.8 \%$ to $47 \%$, respectively. ${ }^{12,14,16,20,22,41}$ Lower dosage (5 mg/d) and shorter duration (12 or 16 weeks) in most of the above studies make Chinese AD patients on donepezil appear to have better safety and tolerability than the patients in the studies in Western countries and Japan (dropout rates $15 \%-32 \%$, AE rates $37 \%-40 \%$ ). ${ }^{8,27,28}$ It has been further observed that donepezil at a dosage of $10 \mathrm{mg} / \mathrm{d}$ can be well tolerated in severe Chinese AD patients, ${ }^{42}$ with a similar withdrawal rate $(22.9 \%$ vs $10 \%-33.5 \%)$ and a lower $\mathrm{AE}$ rate $(26.7 \%$ vs $80.6 \%)$ than Western severe $\mathrm{AD}$ studies. ${ }^{10,39,43-45}$ The most common side effects of donepezil in Chinese AD patients, as shown in Table 2, include dizziness, gastrointestinal symptoms (nausea, loss of appetite, vomiting, 
Table 2 The safety and tolerability of donepezil in Chinese patients with $A D$ or aMCI from previous trials

\begin{tabular}{|c|c|c|c|c|c|c|c|}
\hline Study & Patients & $\begin{array}{l}\text { Dose } \\
(\mathrm{mg} / \mathrm{d})^{\mathrm{a}}\end{array}$ & Duration & $\begin{array}{l}\text { Dropout } \\
(\%)\end{array}$ & $\begin{array}{l}\mathrm{AE} \\
(\%)\end{array}$ & Most common AEs & $\begin{array}{l}\text { Drug-related } \\
\text { SAE }\end{array}$ \\
\hline $\begin{array}{l}\text { Peng et al } \\
(2002)^{12}\end{array}$ & $\begin{array}{l}\text { Mild to } \\
\text { moderate }\end{array}$ & 5 & 12 weeks & 2.8 & 4.8 & $\begin{array}{l}\text { Dizziness, nausea, anorexia, mild diarrhea, } \\
\text { constipation, fatigue, and agitation }\end{array}$ & None \\
\hline $\begin{array}{l}\text { Li et al } \\
(2002)^{14}\end{array}$ & $\begin{array}{l}\text { Mild to } \\
\text { moderate }\end{array}$ & 5 & 12 weeks & 0 & 18.2 & Nausea, anorexia, and dizziness insomnia & None \\
\hline $\begin{array}{l}\text { Hu et al } \\
(2006)^{20}\end{array}$ & $\begin{array}{l}\text { Mild to } \\
\text { moderate }\end{array}$ & 5 & 16 weeks & 6 & 12 & $\begin{array}{l}\text { Abdominal pain, diarrhea, anorexia, nausea, } \\
\text { vomiting, and slight elevation in transaminase }\end{array}$ & None \\
\hline $\begin{array}{l}\text { Cheng et al } \\
(2009)^{18}\end{array}$ & $\begin{array}{l}\text { Mild to } \\
\text { severe }\end{array}$ & 10 & 24 weeks & 15.4 & 41.9 & $\begin{array}{l}\text { Dizziness, nausea, diarrhea, vomiting, anorexia, } \\
\text { constipation, headache, drowsiness, and respiratory } \\
\text { and urinary infections }\end{array}$ & None \\
\hline $\begin{array}{l}\text { Miao et al } \\
(20 I I)^{22}\end{array}$ & $\mathrm{aMCl}$ & 5 & 24 weeks & 0 & 7 & Mild nausea, dizziness, anorexia, and insomnia & None \\
\hline $\begin{array}{l}\text { Zhang et al } \\
(2012)^{16}\end{array}$ & $\begin{array}{l}\text { Mild to } \\
\text { moderate }\end{array}$ & 5 or 10 & 16 weeks & 8.4 & 47 & $\begin{array}{l}\text { Nausea, vomiting, dizziness, diarrhea, anorexia, } \\
\text { and sinus bradycardia }\end{array}$ & $\begin{array}{l}\text { Abnormal liver } \\
\text { function tests }\end{array}$ \\
\hline $\begin{array}{l}\text { Huang et al } \\
(2012)^{13}\end{array}$ & $\begin{array}{l}\text { Mild to } \\
\text { severe }\end{array}$ & 5 or 10 & 72 months & 55.8 & NR & $\begin{array}{l}\text { Nausea, vomiting, loss of appetite, insomnia, } \\
\text { and mild muscle cramps }\end{array}$ & None \\
\hline $\begin{array}{l}\text { Jia et al } \\
(2017)^{42}\end{array}$ & Severe & 10 & 24 weeks & 22.9 & 26.7 & $\begin{array}{l}\text { Sinus bradycardia, anorexia, Q-T interval } \\
\text { prolongation, dizziness, nasopharyngitis, diarrhea, } \\
\text { weight loss, and urinary tract infection }\end{array}$ & None \\
\hline
\end{tabular}

Notes: aFive or $10 \mathrm{mg}$ means a flexible dosage depending on tolerability; $10 \mathrm{mg}$ means titrating to $10 \mathrm{mg}$ after 4-6 weeks of treatment with $5 \mathrm{mg}$.

Abbreviations: $A D$, Alzheimer's disease; $A E$, adverse event; NR, not reported; $S A E$, severe $A E ;$ aMCl, amnestic mild cognitive impairment.

diarrhea, and constipation), insomnia, fatigue, sinus bradycardia, Q-T interval prolongation, abnormal liver function tests, and agitation.

Moreover, most side effects of donepezil spontaneously remitted and it can be well-tolerated in Chinese AD patients in long-term intervention. The main side effects of donepezil were nausea, vomiting, loss of appetite, insomnia, and mild muscle cramps in a 72-month observational study. ${ }^{13}$ Only nine out of 273 patients withdrew from donepezil treatment because of side effects, such as gastrointestinal problems, drowsiness, and insomnia, in a retrospective study of donepezil-treated mild to moderate AD patients from two centers in Kaohsiung from 2004 to 2013. ${ }^{55}$ These results indicate that Chinese AD patients can tolerate long-term donepezil treatment with generally mild and transient AEs just as Caucasian patients in previous studies. ${ }^{29,30,32}$

A double-blind study comparing donepezil and galantamine in Chinese mild to moderate AD patients observed that galantamine had fewer gastrointestinal AEs than donepezil. ${ }^{16}$ However, donepezil exhibited lower incidence of AE rate and withdrawal rate due to $\mathrm{AE}$ compared with oral rivastigmine and galantamine in Caucasian patients according to a systematic review of community and nursing home-dwelling residents. ${ }^{56}$ Many of the comparative studies accepted a flexible dosage of the drugs, such as 5-10 mg/d of donepezil, 8-24 mg/d of galantamine, and 3-12 $\mathrm{mg} / \mathrm{d}$ of oral rivastigmine, causing conflicting results of differences in safety between the three AChEIs. When combined with memantine, there were no significant differences in the $\mathrm{AE}$ rate between donepezil
(31.8\%), galantamine, rivastigmine, huperzine A, and placebo in Chinese patients. ${ }^{17}$ Furthermore, in the previously cited head-to-head study, donepezil showed similar safety as memantine in Chinese mild to severe AD patients. ${ }^{18}$

In conclusion, based on the studies included in this review, donepezil is highly likely to be efficacious for Chinese patients with mild to moderate AD (2 Class I studies) and is possibly effective for Chinese patients with severe AD (1 Class II study). Although three Class III studies suggested that donepezil may have slight benefit on cognition in Chinese patients with aMCI, the level of evidence is insufficient to support this conclusion. Studies addressing efficacy differences between donepezil and other AChEIs or memantine have been inconclusive. The responses to donepezil treatment in Chinese AD patients are variable and may be influenced by APOE genotype or CYP2D6 polymorphism. Moreover, donepezil is generally safe and well tolerated in Chinese AD patients, apart from being mindful of gastrointestinal symptoms, bradycardia, and abnormal liver function.

\section{Acknowledgments}

This work was supported in part by the National Natural Science Foundation of China (grant number 81500926) and the National Key Clinical Specialty Construction Project of China.

\section{Disclosure}

Dr Gordon has served on an advisory board for Lundbeck, as a consultant to Alkermes, and has received research support 
without direct compensation from AbbVie, Eisai, Genentech, Lundbeck, and Merck. The other authors report no conflicts of interest in this work.

\section{References}

1. Jia J, Wang F, Wei C, et al. The prevalence of dementia in urban and rural areas of China. Alzheimers Dement. 2014;10(1):1-9.

2. Zhang ZX, Zahner GE, Román GC, et al. Dementia subtypes in China: prevalence in Beijing, Xian, Shanghai, and Chengdu. Arch Neurol. 2005;62(3):447-453.

3. Yuan J, Zhang Z, Wen H, et al. Incidence of dementia and subtypes: A cohort study in four regions in China. Alzheimers Dement. 2016; 12(3):262-271.

4. Chan KY, Wang W, Wu JJ, et al. Epidemiology of Alzheimer's disease and other forms of dementia in China, 1990-2010: a systematic review and analysis. Lancet. 2013;381(9882):2016-2023.

5. Zhao M, Lv X, Tuerxun M, et al. Delayed help seeking behavior in dementia care: preliminary findings from the Clinical Pathway for Alzheimer's Disease in China (CPAD) study. Int Psychogeriatr. 2016; 28(2):211-219.

6. Peng D, Shi Z, Xu J, et al. Demographic and clinical characteristics related to cognitive decline in Alzheimer disease in China: A multicenter survey from 2011 to 2014. Medicine. 2016;95(26):e3727.

7. Ferreira-Vieira TH, Guimaraes IM, Silva FR, Ribeiro FM. Alzheimer's disease: Targeting the Cholinergic System. Curr Neuropharmacol. 2016;14(1):101-115.

8. Rogers SL, Farlow MR, Doody RS, Mohs R, Friedhoff LT. A 24-week, double-blind, placebo-controlled trial of donepezil in patients with Alzheimer's disease. Donepezil Study Group. Neurology. 1998; 50(1):136-145.

9. Feldman H, Gauthier S, Hecker J, et al. A 24-week, randomized, doubleblind study of donepezil in moderate to severe Alzheimer's disease. Neurology. 2001;57(4):613-620.

10. Black SE, Doody R, Li H, et al. Donepezil preserves cognition and global function in patients with severe Alzheimer disease. Neurology. 2007;69(5):459-469.

11. Liu HC, Hong CJ, Wang SJ, et al. ApoE genotype in relation to AD and cholesterol: a study of 2,326 Chinese adults. Neurology. 1999; 53(5):962-966.

12. Peng D, Xu X, Hou Q. The safety and efficacy of aricept in patients with Alzheimer disease. Zhonghua Shen Jing Ke Za Zhi. 2002; 35(1):19-21.

13. Huang H, Li M, Jiang G, Mu X, Chen Q. Long-term efficacy observation of donepezil in the treatment of Alzheimer's disease. Zhonghua Lao Nian Yi Xue Za Zhi. 2012;31(2):98-101.

14. Li D, Zhang Z, Zhang M. A comparative study of donepezil and tacrine in treatment of Alzheimer disease. Zhonghua Jing Shen Ke Za Zhi. 2002;35(4):216-219.

15. Yang YH, Wu MN, Chou PS, Su HC, Lin SH, Sung PS. Longitudinal Neuropsychological Outcome in Taiwanese Alzheimer's Disease Patients Treated with Medication. Curr Alzheimer Res. 2018;15(5): 474-481.

16. Zhang Z, Yu L, Gaudig M, Schäuble B, Richarz U. Galantamine versus donepezil in Chinese patients with Alzheimer's disease: results from a randomized, double-blind study. Neuropsychiatr Dis Treat. 2012;8:571-577.

17. Shao ZQ. Comparison of the efficacy of four cholinesterase inhibitors in combination with memantine for the treatment of Alzheimer's disease. Int J Clin Exp Med. 2015;8(2):2944-2948.

18. Cheng Y, Zhang N, Du H. Multicenter controlled randomized clinical trial of akatinol memantine for treatment of Alzheimer's disease. Zhonghua Shen Jing Ke Za Zhi. 2009;42(4):268-272.

19. Zhang N, Wei C, Du H, Shi FD, Cheng Y. The Effect of Memantine on Cognitive Function and Behavioral and Psychological Symptoms in Mild-to-Moderate Alzheimer's Disease Patients. Dement Geriatr Cogn Disord. 2015;40(1-2):85-93.
20. Hu HT, Zhang ZX, Yao JL, et al. Clinical efficacy and safety of akatinol memantine in treatment of mild to moderate Alzheimer disease: a donepezil-controlled, randomized trial. Zhonghua Nei Ke Za Zhi. 2006;45(4):277-280.

21. Wang LN, Wang W, Zhang XH, Ma L, Yin H, Li DJ. An interventional study on amnestic mild cognitive impairment with small dose donepezil. Zhonghua Nei Ke Za Zhi. 2004;43(10):760-763.

22. Miao Y, Zhong Y, Yan H. Comparative clinical effectiveness of donepezil versus huperzine in elderly patients with mild cognitive impairment. Zhonghua Lao Nian Yi Xue Za Zhi. 2011;30(10):808-811.

23. Zhao J, Zhao J. Effect of donepezil hydrochloride on changes of cognitive function and Montreal cognitive assessment scores in patients with mild cognitive impairment. Zhonghua Shen Jing Yi Xue Za Zhi. 2012;11(9):936-938.

24. Chang YS, Chen HL, Hsu CY, Tang SH, Liu CK. Parallel improvement of cognitive functions and P300 latency following donepezil treatment in patients with Alzheimer's disease: a case-control study. J Clin Neurophysiol. 2014;31(1):81-85.

25. Ma Y, Ji J, Li G, Yang S, Pan S. Effects of donepezil on cognitive functions and the expression level of $\beta$-amyloid in peripheral blood of patients with Alzheimer's disease. Exp Ther Med. 2018;15(2):1875-1878.

26. Li N, Wang J, Ma J, et al. Neuroprotective Effects of Cistanches Herba Therapy on Patients with Moderate Alzheimer's Disease. Evid Based Complement Alternat Med. 2015;2015:103985:1-12.

27. Homma A, Takeda M, Imai Y, et al. Clinical efficacy and safety of donepezil on cognitive and global function in patients with Alzheimer's disease. A 24-week, multicenter, double-blind, placebo-controlled study in Japan. E2020 Study Group. Dement Geriatr Cogn Disord. 2000; 11(6):299-313.

28. Burns A, Rossor M, Hecker J. The effects of donepezil in Alzheimer's disease - results from a multinational trial. Dement Geriatr Cogn Disord May. 1999;10(3):237-244.

29. Rogers SL, Doody RS, Pratt RD, Ieni JR. Long-term efficacy and safety of donepezil in the treatment of Alzheimer's disease: final analysis of a US multicentre open-label study. Eur Neuropsychopharmacol. 2000;10(3):195-203.

30. Doody RS, Geldmacher DS, Gordon B, Perdomo CA, Pratt RD, Donepezil Study Group. Open-label, multicenter, phase 3 extension study of the safety and efficacy of donepezil in patients with Alzheimer disease. Arch Neurol. 2001;58(3):427-433.

31. Courtney C, Farrell D, Gray R, et al. Long-term donepezil treatment in 565 patients with Alzheimer's disease (AD2000): randomised doubleblind trial. Lancet. 2004;363(9427):2105-2115.

32. Winblad B, Wimo A, Engedal K, et al. 3-year study of donepezil therapy in Alzheimer's disease: effects of early and continuous therapy. Dement Geriatr Cogn Disord. 2006;21(5-6):353-363.

33. Salloway S, Ferris S, Kluger A, et al. Efficacy of donepezil in mild cognitive impairment: a randomized placebo-controlled trial. Neurology. 2004;63(4):651-657.

34. Petersen RC, Thomas RG, Grundman M, et al. Vitamin E and donepezil for the treatment of mild cognitive impairment. $N$ Engl J Med. 2005; 352(23):2379-2388.

35. Doody RS, Ferris SH, Salloway S, et al. Donepezil treatment of patients with MCI: a 48-week randomized, placebo-controlled trial. Neurology. 2009;72(18):1555-1561.

36. Schuff N, Suhy J, Goldman R, et al. An MRI substudy of a donepezil clinical trial in mild cognitive impairment. Neurobiol Aging. 2011; 32(12):2318.e31-2318.e41.

37. Dubois B, Chupin M, Hampel H, et al. Donepezil decreases annual rate of hippocampal atrophy in suspected prodromal Alzheimer's disease. Alzheimers Dement. 2015;11(9):1041-1049.

38. García-Ayllón MS, Silveyra MX, Andreasen N, Brimijoin S, Blennow K, Sáez-Valero J. Cerebrospinal fluid acetylcholinesterase changes after treatment with donepezil in patients with Alzheimer's disease. JNeurochem. 2007;101(6):1701-1711.

39. Winblad B, Kilander L, Eriksson S, et al. Donepezil in patients with severe Alzheimer's disease: double-blind, parallel-group, placebocontrolled study. Lancet. 2006;367(9516):1057-1065. 
40. Howard R, Mcshane R, Lindesay J, et al. Donepezil and memantine for moderate-to-severe Alzheimer's disease. $N$ Engl J Med. 2012; 366(10):893-903.

41. Peng D, Yu P. A survey of the consultative status of patients with Alzheimer disease and the efficacy and safety of donepezil treatment. Zhonghua Lao Nian Yi Xue Za Zhi. 2010;29(8):691-693.

42. Jia J, Wei C, Jia L, et al. Efficacy and Safety of Donepezil in Chinese Patients with Severe Alzheimer's Disease: A Randomized Controlled Trial. J Alzheimers Dis. 2017;56(4):1495-1504.

43. Feldman H, Gauthier S, Hecker J, et al. Efficacy and safety of donepezil in patients with more severe Alzheimer's disease: a subgroup analysis from a randomized, placebo-controlled trial. Int J Geriatr Psychiatry. 2005;20(6):559-569.

44. Cummings J, Jones R, Wilkinson D, et al. Effect of donepezil on cognition in severe Alzheimer's disease: a pooled data analysis. J Alzheimers Dis. 2010;21(3):843-851.

45. Homma A, Imai Y, Tago H, et al. Donepezil treatment of patients with severe Alzheimer's disease in a Japanese population: results from a 24-week, double-blind, placebo-controlled, randomized trial. Dement Geriatr Cogn Disord. 2008;25(5):399-407.

46. Yang YH, Wu SL, Chou MC, Lai CL, Chen SH, Liu CK. Plasma concentration of donepezil to the therapeutic response of Alzheimer's disease in Taiwanese. J Alzheimers Dis. 2011;23(3):391-397.

47. Yang YH, Chen CH, Chou MC, Li CH, Liu CK, Chen SH. Concentration of donepezil to the cognitive response in Alzheimer disease. J Clin Psychopharmacol. 2013;33(3):351-355.

48. Wu MN, Kao YH, Chou PS, Lin TC, Kao LL, Yang YH. Location of white matter changes and response to donepezil in patients with Alzheimer's disease: A retrospective and observational study. Geriatr Gerontol Int. 2018;18(1):123-129.

49. Liu M, Zhang Y, Huo YR, et al. Influence of the rs1080985 Single Nucleotide Polymorphism of the CYP2D6 Gene and APOE Polymorphism on the Response to Donepezil Treatment in Patients with Alzheimer's Disease in China. Dement Geriatr Cogn Dis Extra. 2014;4(3): $450-456$.
50. Zhong Y, Zheng X, Miao Y, Wan L, Yan H, Wang B. Effect of CYP2D6*10 and APOE polymorphisms on the efficacy of donepezil in patients with Alzheimer's disease. Am J Med Sci. 2013;345(3): 222-226.

51. Lu J, Wan L, Zhong Y, et al. Stereoselective metabolism of donepezil and steady-state plasma concentrations of S-donepezil based on CYP2D6 polymorphisms in the therapeutic responses of Han Chinese patients with Alzheimer's disease. J Pharmacol Sci. 2015;129(3):188-195.

52. Lu J, Fu J, Zhong Y, et al. The roles of apolipoprotein E3 and CYP2D6 (rs1065852) gene polymorphisms in the predictability of responses to individualized therapy with donepezil in Han Chinese patients with Alzheimer's disease. Neurosci Lett. 2016;614:43-48.

53. Lu J, Fu J, Zhong Y, et al. Association between ABCA1 gene polymorphisms and the therapeutic response to donepezil therapy in Han Chinese patients with Alzheimer's disease. Brain Res Bull. 2018;140:1-4.

54. Xiao T, Jiao B, Zhang W, Tang B, Shen L. Effect of the CYP2D6 and APOE Polymorphisms on the Efficacy of Donepezil in Patients with Alzheimer's Disease: A Systematic Review and Meta-Analysis. CNS Drugs. 2016;30(10):899-907.

55. Chang YP, Yang CH, Chou MC, Chen CH, Yang YH. Clinical compliance of donepezil in treating Alzheimer's disease in Taiwan. Am J Alzheimers Dis Other Demen. 2015;30(4):346-351.

56. Lockhart IA, Mitchell SA, Kelly S. Safety and tolerability of donepezil, rivastigmine and galantamine for patients with Alzheimer's disease: systematic review of the 'real-world' evidence. Dement Geriatr Cogn Disord. 2009;28(5):389-403.
Clinical Interventions in Aging

\section{Publish your work in this journal}

Clinical Interventions in Aging is an international, peer-reviewed journal focusing on evidence-based reports on the value or lack thereof of treatments intended to prevent or delay the onset of maladaptive correlates of aging in human beings. This journal is indexed on PubMed Central, MedLine,

\section{Dovepress}

CAS, Scopus and the Elsevier Bibliographic databases. The manuscript management system is completely online and includes a very quick and fair peer-review system, which is all easy to use. Visit http://www.dovepress. com/testimonials.php to read real quotes from published authors. 